\title{
The simulation analysis of torque ripple reduction by using optimal voltage vector in DTC fed by five-level CHB inverter
}

\author{
Siti Azura A. Tarusan ${ }^{1}$, Auzani Jidin², Mohd Luqman M. Jamil ${ }^{3}$ \\ 1,2,3Faculty of Electrical Engineering, Universiti Teknikal Malaysia Melaka (UTeM), Malaysia \\ ${ }^{1,2}$ Power Electronics and Drives Research Group, CeRIA, UTeM, Malaysia \\ ${ }^{3}$ Electrical Machine Design, Power Electronics and Drives Research Group, CeRIA, UTeM, Malaysia
}

\begin{tabular}{l} 
Article Info \\
\hline Article history: \\
Received May 1, 2020 \\
Revised Jul 29, 2020 \\
Accepted Aug 1, 2020 \\
\hline Keywords: \\
AC drives \\
Direct torque control \\
Multilevel inverter \\
Torque ripple \\
Voltage vectors
\end{tabular}

\begin{abstract}
In this paper, the improvement of torque ripple reduction will be focused based on the optimal voltage vector. This is attained by using five-level CHB inverter that applies in DTC drive control as a proposed method. The analysis is performed and simulated by using MATLAB/Simulink. In order to support the analysis, the comparison is realized between proposed method and conventional method which it applies two-level inverter. It will be analysed at constant torque region or steady-state operation on different range of operating speed which the speed is controlled by adjusting the motor load. Meaning that, the speed controller is neglected during analysis. Nevertheless, the adjustment of motor load must be applicable to the optimal voltage vector. The look-up table of five-level CHB inverter will become a guideline to select the optimal voltage vector. Therefore, it can maintain the simple structure of DTC hysteresis-based that fed by using five-level CHB inverter. As a result, the torque ripple can be minimized and torque capability can be retained even at low operating speed compared to the conventional DTC.
\end{abstract}

Copyright $@ 2020$ Institute of Advanced Engineering and Science. All rights reserved.

\section{Corresponding Author:}

Siti Azura Binti Ahmad Tarusan, Faculty of Electrical Engineering, Universiti Teknikal Malaysia Melaka, 76100 Durian Tunggal, Melaka, Malaysia. Email: sitiazura@utem.edu.my

\section{INTRODUCTION}

Drive control is a significant element to drive an AC machine by considering the good reliability,robust and efficient performance. Hence, AC drive control is classified into two main categories; 1) scalar control and, 2) vector control. Scalar control was introduced in 1984 by Bose [1] where the voltagecontrolled PWM for inverter was applied to drive the induction motor. Scalar control method mostly was robust in steady state rather than dynamic performance as claimed in [2]. However, it remains utilized in recent studies as discussed in $[3,4]$. The common vector control method to drive the AC machine presently is field-oriented control (FOC) and direct torque control (DTC). FOC introduced by Hasse and Blaschke is popular drive control where the synchronous rotation of $\mathrm{d}-\mathrm{q}$ model is employed to enable the ac machine to be identical with de machine during steady-state condition [1, 5]. Thus, it contributes to the high accuracy and outstanding drive control performance as referred in [6-9]. Nevertheless, its challenge is the value of instantaneous position must be accurate in order to calculate the stator voltage vector at the coordinate transformation in drive system. Alternatively, DTC introduced by Takahashi and Naguchi as shown in Figure 1 is more favor due to its simple control method and less computation burden compared to FOC $[10,11]$. Although DTC has excellent attributes, but its problems such as variable switching frequency, high torque and flux ripple and also poor stator flux regulation are the contraints to the DTC drive system. 
Various approaches have been suggested to solve the problems like multilevel inverter, carrier frequency, space vector modulation, duty ratio modulation etc.

Multilevel inverter (MLI) becomes applicable in the medium- and high-power applications such as automation, heavy-duty and aerospace applications due to several reasons like low voltage dv/dt stress, low harmonics and smooth sinusoidal output voltage rather than conventional inverter [12-16]. Even in the DTC control, it enables to minimize the ripple of torque and flux performance [10]. In general, total voltage vector produced by conventional or two-level inverter is eight thus it limits the variation of voltage vector for the inverter switching. By employing MLI, the voltage vector increases thus large degree of freedom for optimal switching can be achieved [17]. Several topologies of MLI have been developed and employed in DTC as studied in [18-23]. On the other hand, Space Vector Pulse Width Modulation (SVPWM) strategy is another approach employed in DTC (DTC-SVM). It is a common strategy applied in FOC which it controls the decouple direct and quadrature stator current by using PI controller. Later, this strategy employed in DTC except the decouple variable controlled is changed to the electromagnetic torque and stator flux as referred in [24]. Although SVM contributes the torque ripple reduction and constant switching frequency in DTC but it suffers in terms of the complicated control structure and precise digital control processing. Several studies about DTC-SVM developments can be referred in [18, 19]. Besides SVM, fixed or constant switching frequency is introduced and achieved by using triangular waveform or carrier frequency. This method replaces the hysteresis comparator of torque controller in DTC and neglects the complicated operation and high processing burden caused by SVM as in [20, 25, 26]. However, the slope of the PI controller error must not exceed the slope of triangular waveform in producing a constant switching. Otherwise, the excessive of PI error slope consequences to the large torque ripple in DTC. Duty cycle-based strategy is another typical approach to improve the performance of DTC as proposed in [21, 27, 28]. It enables to manipulate the voltage vectors within their stipulated time in each interval switching that directly able to control the torque slope profile. Although it manages to minimize the torque ripple however it involves the complex calculation and can cause switching losses due to the utilization of several voltage vector.

As for motivation, the improvement of torque ripple reduction will be focused based on the optimal voltage vector. This is attained by using five-level CHB inverter that applies in DTC drive control as a proposed method. The analysis is performed and simulated by using MATLAB/Simulink. In order to support the analysis, the comparison is realized between proposed method and conventional method which it applies two-level inverter. It will be analysed at constant torque region or steady-state operation on different range of operating speed which the speed is controlled by adjusting the motor load. Meaning that, the speed controller is neglected during analysis. Nevertheless, the adjustment of motor load must be applicable to the optimal voltage vector. The look-up table of five-level $\mathrm{CHB}$ inverter will become a guideline to select the optimal voltage vector. Therefore, it can maintain the simple structure of DTC hysteresis-based that fed by using fivelevel CHB inverter. In addition, the torque ripple can be minimized and motor can operate at low operating speed compared to the conventional DTC.

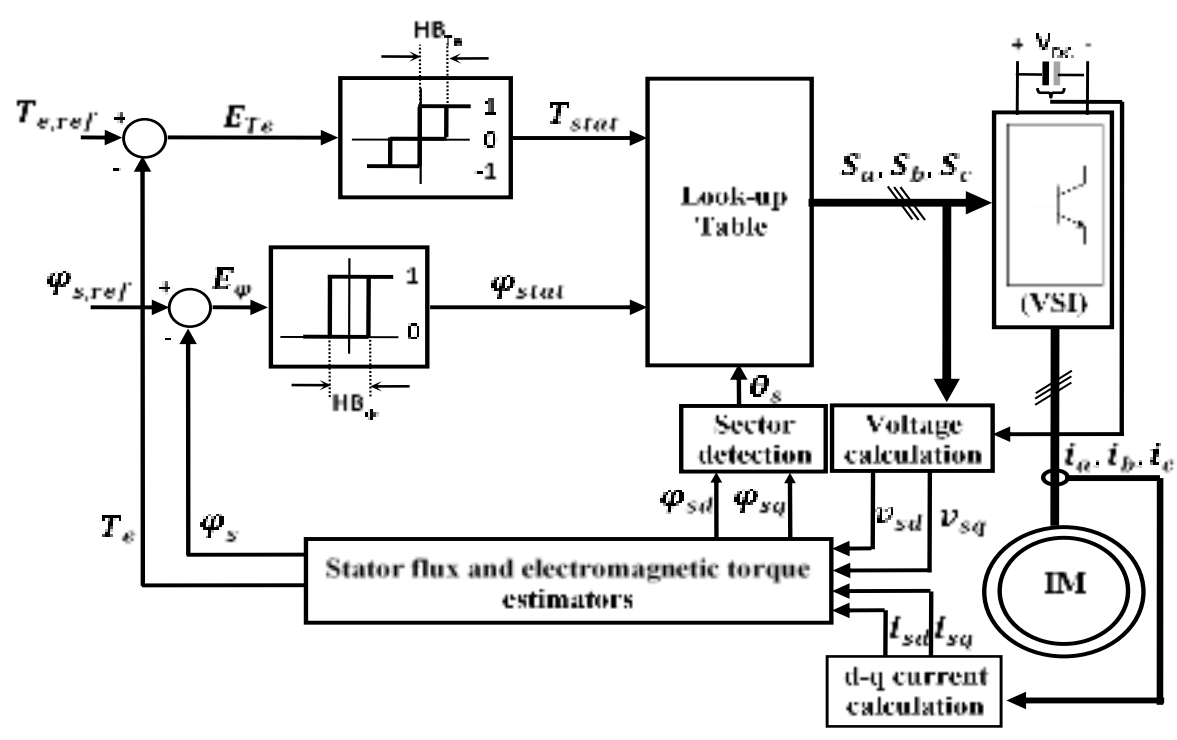

Figure 1. The structure diagram of DTC drive control [11] 


\section{BASIC PRIINCIPAL OF DTC}

Figure 1 illustrates the structure diagram of DTC drive control as proposed in [11].The control structure is constructed by using a pair of hysteresis controllers, a look-up table, two-level inverter, torque and flux estimators which obtain the information of voltage and current to perform the detected sector, estimated torque and flux. Two-level and three-level hysteresis represent for the flux and torque controller. The look-up table contains the status of torque, flux and sector in order to perform the selected voltage vector to run the inverter. Two-level inverter in the conventional DTC performs eight voltage vectors as arranged in mapping vector shown in Figure 2(a). It consists of two zero voltage vectors (V0 and V7) and six active voltage vectors (V1-V6) with their particular switching signal of ' 1 ' and ' 0 ' (ON and OFF operation). These vectors are responsible to control the performance of flux and torque that controlled through the orientation of stator flux locus shown in Figure 2(b). The locus is divided into six sectors which only two possible voltage vectors are allowed to control the stator flux vector either increase or decrease on each sector. The more tangential vectors to the flux component are encouraged to be selected for giving the best torque response in DTC [11]. Therefore, the torque response performance is influenced by the variation of stator flux as well as the variation of load angle between stator and rotor flux vector.

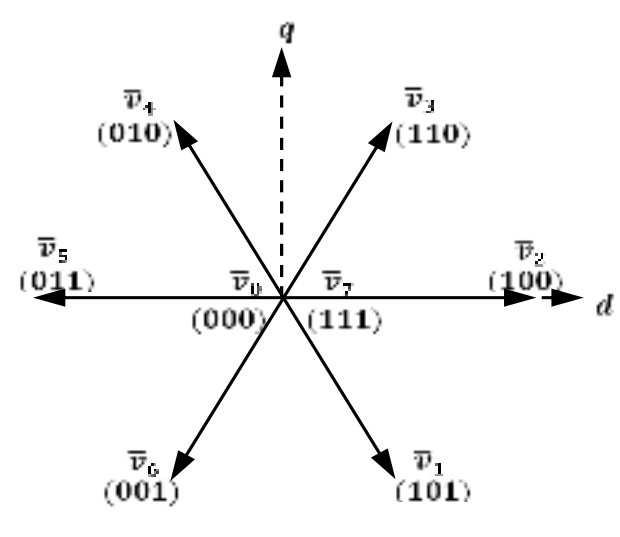

(a)

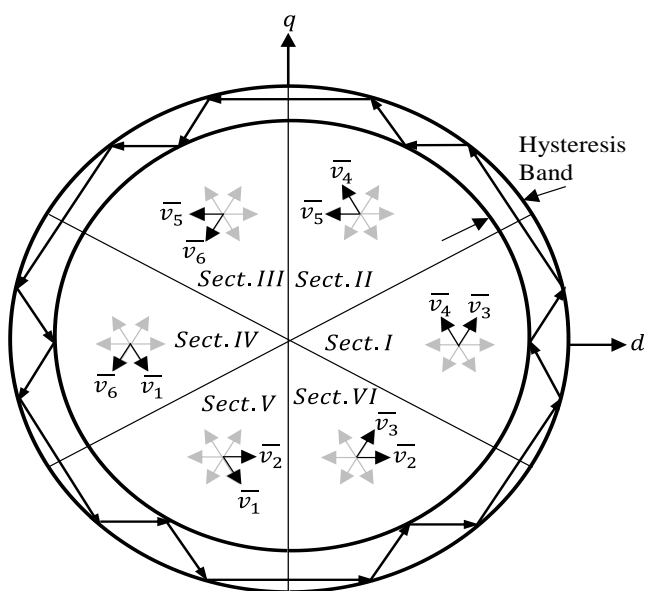

(b)

Figure 2. Voltage vectors (a) in mapping vectors and, (b) orientation in the stator flux locus [11]

\section{DTC FED BY FIVE-LEVEL CHB INVERTER}

Figure 3(a) illustrates the schematic of Five-level Cascaded H-Bridge inverter which it replaces the two-level inverter in conventional DTC to be realized as a proposed method. The voltage vectors are denoted by the upper switches as $\left[\mathrm{S}_{\mathrm{a} 1}{ }^{+}, \mathrm{S}_{\mathrm{a} 2}{ }^{+}, \mathrm{S}_{\mathrm{a} 3}{ }^{+}, \mathrm{S}_{\mathrm{a} 4}{ }^{+}\right]$for the phase $\mathrm{a},\left[\mathrm{S}_{\mathrm{b} 1}{ }^{+}, \mathrm{S}_{\mathrm{b} 2}{ }^{+}, \mathrm{S}_{\mathrm{b} 3}{ }^{+}, \mathrm{S}_{\mathrm{b} 4}{ }^{+}\right]$for the phase $\mathrm{b}$ and $\left[\mathrm{S}_{\mathrm{c} 1}{ }^{+}, \mathrm{S}_{\mathrm{c} 2}{ }^{+}, \mathrm{S}_{\mathrm{c} 3}{ }^{+}, \mathrm{S}_{\mathrm{c} 4}{ }^{+}\right]$for the phase $\mathrm{c}$. While the lower switches are the complimentary switch. Therefore, the d-q stator voltage in five-level CHB is expressed in (1) and (2). All of the voltage vector is possible to be employed as the switching states for the inverter. Hence, the mapping voltage vector of five-level CHB inverter is performed as shown in Figure 3(b). In the figure, it contains the total of 61 vectors which eventually only the red highlighted voltage vectors are selected to become as the tangential vectors. Further, the identification of flux sectors and look-up table for all the tangential vectors will be discussed on the following section.

$$
\begin{aligned}
& v_{s d}=\frac{V_{D C}}{3}\left[2\left(S_{a 1}{ }^{+}-S_{a 2}{ }^{+}\right)+2\left({S_{a 3}}^{+}-S_{a 4}{ }^{+}\right)-\left({S_{b 1}}^{+}-S_{b 2}{ }^{+}\right)-\left(S_{b 3}{ }^{+}-S_{b 4}{ }^{+}\right)-\left(S_{c 1}{ }^{+}-\right.\right. \\
& \left.\left.S_{c 2}{ }^{+}\right)-\left({S_{c 3}}^{+}-S_{c 4}{ }^{+}\right)\right] \\
& v_{s q}=\frac{V_{D C}}{\sqrt{3}}\left[\left({S_{b 1}}^{+}-S_{b 2}{ }^{+}\right)+\left({S_{b 3}}^{+}-{S_{b 4}}^{+}\right)-\left({S_{c 1}}^{+}-S_{c 2}{ }^{+}\right)-\left({S_{c 3}}^{+}-S_{c 4}{ }^{+}\right)\right]
\end{aligned}
$$




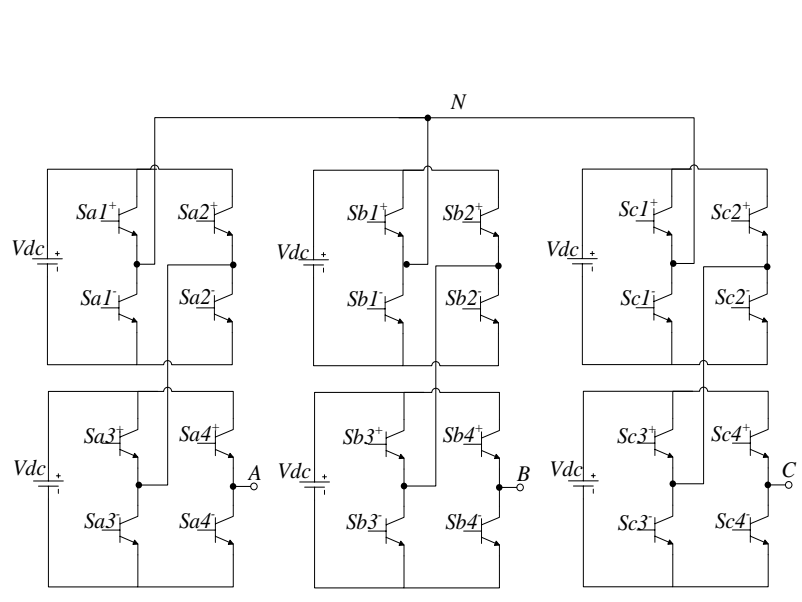

(a)

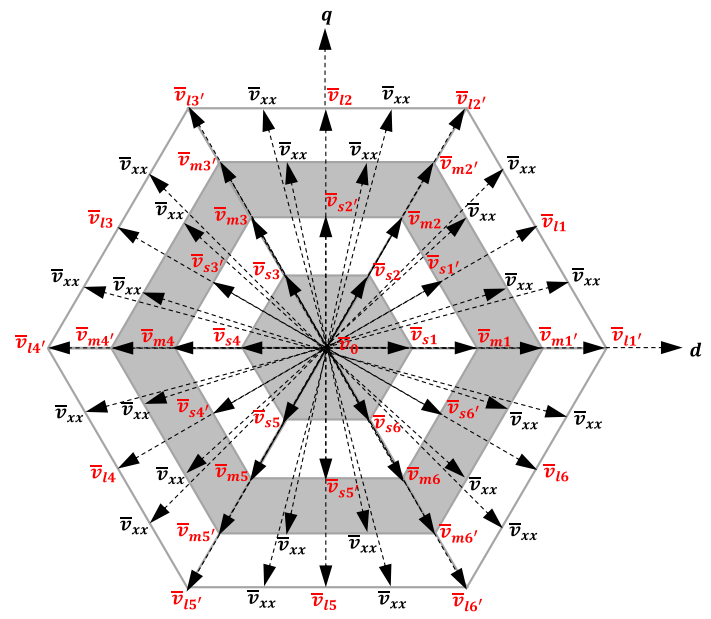

(b)

Figure 3. Five-level CHB inverter (a) schematic and, (b) mapping vectors

\subsection{The identification of flux sectors}

In order to arrange the tangential vector into look-up table, the flux sector must be defined properly to coordinate the appropriate voltage vector that contributes the good torque performance of DTC. Hence, two definition flux sectors have been proposed as shown in Figure 4. Both circulars are divided into $60^{\circ}$ which the different orientation between them is $30^{\circ}$. One of them is aligned to the q-axis direction while the other is aligned to the d-axis direction. Also, each sector is compared through threshold value of each sector (boundary of each sector) by using the estimated flux in $\mathrm{d}-\mathrm{q}$ form. Based on the both figures, the threshold value are denoted by $0, \varphi_{\mathrm{sd} 1}$ and $\varphi_{\mathrm{sq} 1}$. It is known that five-level mapping vector is consisted of four hexagonal diagrams. The amplitude level of hexagonal diagram increases from the origin of the plane towards to the outer of hexagonal diagram. As referred in Figure 4(a), the n-vector on each corner of hexagonal level $\left(\overline{\mathrm{v}}_{\mathrm{sn}}, \overline{\mathrm{v}}_{\mathrm{mn}}, \overline{\mathrm{v}}_{\mathrm{mn}^{\prime}}\right.$ and $\left.\overline{\mathrm{v}}_{\mathrm{ln}^{\prime}}\right)$ is tangential to the flux sector that aligned into q-axis direction. Each sector shows the direction level of voltage vector to increase and decrease flux. Thus, the q-axis sector has employed 24 voltage vectors. Meanwhile, for the flux sector in the d-axis direction shown in Figure 4(b), the middle vector of each corner hexagonal $\left(\overline{\mathrm{v}}_{\mathrm{sn}}{ }^{\prime}\right.$ and $\left.\overline{\mathrm{v}}_{\mathrm{ln}}\right)$ is selected to be tangential into this sector. It has performed 12 voltage vectors. In shorten, there will be 37 voltage vectors as the tangential vector including one zero vector in the origin plane utilized in the look-up table of five-level DTC.

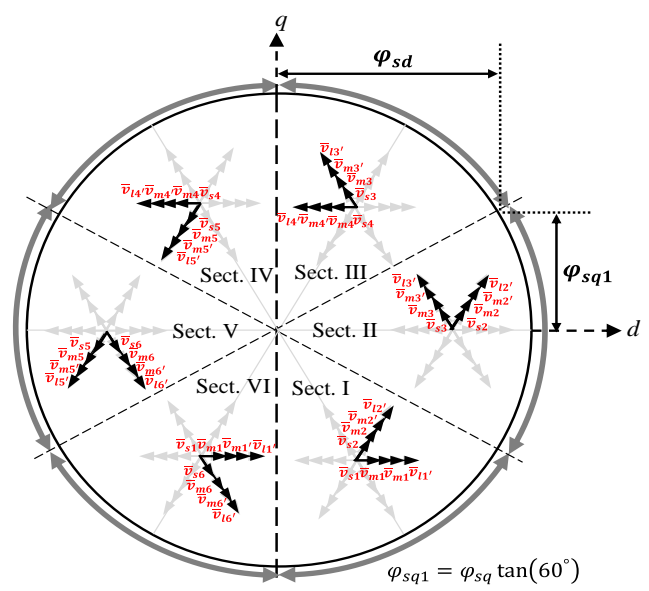

(a)

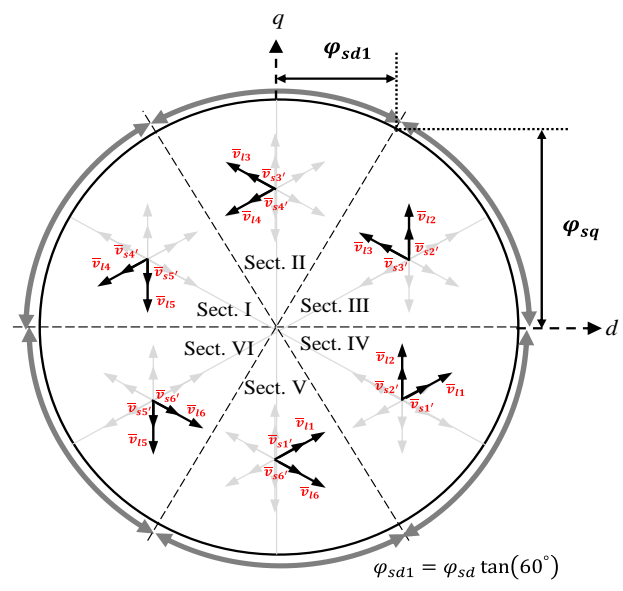

(b)

Figure 4. The identification of vectors in flux sectors on (a) q-axis and, (b) d-axis direction 


\subsection{Look-up table}

As discussed in the previous section, the tangential voltage vectors as well as the coordination of flux sector have been defined suitably. All the voltage vectors mapped in the look-up table of Table 1 is comprised with the stator flux error status, $\sigma_{\varphi_{\text {stat }}}$, torque error status, $\sigma_{\mathrm{T}_{\text {stat }}}$ and sector, $\theta_{\mathrm{n}}$. The flux controller will regulate the flux to produce the error status of ' 1 ' or ' 0 ' to represent the increase or decrease flux. For the torque controller, the torque error status is arranged regardless of the vector length as determined by the aforementioned sector. Hence, there are 13 level of torque error status involving the zero status, positive status (i.e $+1,+2,+3,+4,+5,+6)$ and negative status (i.e $-1,-2,-3,-4,-5,-6)$. The positive and negative status represent for the clockwise and counter clockwise direction respectively of motor.

Table 1. The look-up table of DTC fed by five-level CHB inverter

\begin{tabular}{|c|c|c|c|c|c|c|c|}
\hline \multirow{2}{*}{$\sigma_{\varphi_{\text {stat }}}$} & \multirow{2}{*}{$\sigma_{T_{\text {stat }}}$} & \multicolumn{6}{|c|}{$\theta_{n}$} \\
\hline & & I & II & III & IV & V & VI \\
\hline \multirow{12}{*}{+1} & +6 & $\bar{v}_{l 1^{\prime}}$ & $\bar{v}_{l 2^{\prime}}$ & $\bar{v}_{l 3^{\prime}}$ & $\bar{v}_{l 4^{\prime}}$ & $\bar{v}_{l 5^{\prime}}$ & $\bar{v}_{l 6^{\prime}}$ \\
\hline & +5 & $\bar{v}_{l 4}$ & $\bar{v}_{l 3}$ & $\bar{v}_{l 2}$ & $\bar{v}_{l 1}$ & $\bar{v}_{l 6}$ & $\bar{v}_{l 5}$ \\
\hline & +4 & $\bar{v}_{m 1^{\prime}}$ & $\bar{v}_{m 2^{\prime}}$ & $\bar{v}_{m 3^{\prime}}$ & $\bar{v}_{m 4^{\prime}}$ & $\bar{v}_{m 5^{\prime}}$ & $\bar{v}_{m 6^{\prime}}$ \\
\hline & +3 & $\bar{v}_{m 1}$ & $\bar{v}_{m 2}$ & $\bar{v}_{m 3}$ & $\bar{v}_{m 4}$ & $\bar{v}_{m 5}$ & $\bar{v}_{m 6}$ \\
\hline & +2 & $\bar{v}_{s 4^{\prime}}$ & $\bar{v}_{s 3^{\prime}}$ & $\bar{v}_{s 2^{\prime}}$ & $\bar{v}_{s 1^{\prime}}$ & $\bar{v}_{s 6^{\prime}}$ & $\bar{v}_{s 5^{\prime}}$ \\
\hline & +1 & $\bar{v}_{s 1}$ & $\bar{v}_{s 2}$ & $\bar{v}_{s 3}$ & $\bar{v}_{s 4}$ & $\bar{v}_{s 5}$ & $\bar{v}_{s 6}$ \\
\hline & 0 & $\bar{v}_{0}$ & $\bar{v}_{0}$ & $\bar{v}_{0}$ & $\bar{v}_{0}$ & $\bar{v}_{0}$ & $\bar{v}_{0}$ \\
\hline & -1 & $\bar{v}_{s 5}$ & $\bar{v}_{s 6}$ & $\bar{v}_{s 1}$ & $\bar{v}_{s 2}$ & $\bar{v}_{s 3}$ & $\bar{v}_{s 4}$ \\
\hline & -2 & $\bar{v}_{s 2^{\prime}}$ & $\bar{v}_{s 1^{\prime}}$ & $\bar{v}_{s 6^{\prime}}$ & $\bar{v}_{s 5^{\prime}}$ & $\bar{v}_{s 4^{\prime}}$ & $\bar{v}_{s 3^{\prime}}$ \\
\hline & -3 & $\bar{v}_{m 5}$ & $\bar{v}_{m 6}$ & $\bar{v}_{m 1}$ & $\bar{v}_{m 2}$ & $\bar{v}_{m 3}$ & $\bar{v}_{m 4}$ \\
\hline & -4 & $\bar{v}_{m 5^{\prime}}$ & $\bar{v}_{m 6^{\prime}}$ & $\bar{v}_{m 1^{\prime}}$ & $\bar{v}_{m 2^{\prime}}$ & $\bar{v}_{m 3^{\prime}}$ & $\bar{v}_{m 4^{\prime}}$ \\
\hline & -5 & $\bar{v}_{l 2}$ & $\bar{v}_{l 1}$ & $\bar{v}_{l 6}$ & $\bar{v}_{l 5}$ & $\bar{v}_{l 4}$ & $\bar{v}_{l 3}$ \\
\hline \multirow{14}{*}{0} & -6 & $\bar{v}_{l 5^{\prime}}$ & $\bar{v}_{l 6^{\prime}}$ & $\bar{v}_{l 1^{\prime}}$ & $\bar{v}_{l 2^{\prime}}$ & $\bar{v}_{l 3^{\prime}}$ & $\bar{v}_{l 4^{\prime}}$ \\
\hline & +6 & $\bar{v}_{l 2^{\prime}}$ & $\bar{v}_{l 3^{\prime}}$ & $\bar{v}_{l 4^{\prime}}$ & $\bar{v}_{l 5^{\prime}}$ & $\bar{v}_{l 6^{\prime}}$ & $\bar{v}_{l 1^{\prime}}$ \\
\hline & +5 & $\bar{v}_{l 5}$ & $\bar{v}_{l 4}$ & $\bar{v}_{l 3}$ & $\bar{v}_{l 2}$ & $\bar{v}_{l 1}$ & $\bar{v}_{l 6}$ \\
\hline & +4 & $\bar{v}_{m 2^{\prime}}$ & $\bar{v}_{m 3^{\prime}}$ & $\bar{v}_{m 4^{\prime}}$ & $\bar{v}_{m 5^{\prime}}$ & $\bar{v}_{m 6^{\prime}}$ & $\bar{v}_{m 1^{\prime}}$ \\
\hline & +3 & $\bar{v}_{m 2}$ & $\bar{v}_{m 3}$ & $\bar{v}_{m 4}$ & $\bar{v}_{m 5}$ & $\bar{v}_{m 6}$ & $\bar{v}_{m 1}$ \\
\hline & +2 & $\bar{v}_{s 5^{\prime}}$ & $\bar{v}_{s 4^{\prime}}$ & $\bar{v}_{S 3^{\prime}}$ & $\bar{v}_{s 2^{\prime}}$ & $\bar{v}_{s 1^{\prime}}$ & $\bar{v}_{s 6^{\prime}}$ \\
\hline & +1 & $\bar{v}_{s 2}$ & $\bar{v}_{s 3}$ & $\bar{v}_{S 4}$ & $\bar{v}_{S 5}$ & $\bar{v}_{s 6}$ & $\bar{v}_{s 1}$ \\
\hline & 0 & $\bar{v}_{0}$ & $\bar{v}_{0}$ & $\bar{v}_{0}$ & $\bar{v}_{0}$ & $\bar{v}_{0}$ & $\bar{v}_{0}$ \\
\hline & -1 & $\bar{v}_{s 4}$ & $\bar{v}_{s 5}$ & $\bar{v}_{s 6}$ & $\bar{v}_{s 1}$ & $\bar{v}_{s 2}$ & $\bar{v}_{s 3}$ \\
\hline & -2 & $\bar{v}_{S 1^{\prime}}$ & $\bar{v}_{s 6^{\prime}}$ & $\bar{v}_{s 5^{\prime}}$ & $\bar{v}_{s 4^{\prime}}$ & $\bar{v}_{s 3^{\prime}}$ & $\bar{v}_{s 2^{\prime}}$ \\
\hline & -3 & $\bar{v}_{m 4}$ & $\bar{v}_{m 5}$ & $\bar{v}_{m 6}$ & $\bar{v}_{m 1}$ & $\bar{v}_{m 2}$ & $\bar{v}_{m 3}$ \\
\hline & -4 & $\bar{v}_{m 4^{\prime}}$ & $\bar{v}_{m 5^{\prime}}$ & $\bar{v}_{m 6^{\prime}}$ & $\bar{v}_{m 1^{\prime}}$ & $\bar{v}_{m 2^{\prime}}$ & $\bar{v}_{m 3^{\prime}}$ \\
\hline & -5 & $\bar{v}_{l 1}$ & $\bar{v}_{l 6}$ & $\bar{v}_{l 5}$ & $\bar{v}_{l 4}$ & $\bar{v}_{l 3}$ & $\bar{v}_{l 2}$ \\
\hline & -6 & $\bar{v}_{l 4^{\prime}}$ & $\bar{v}_{l 5^{\prime}}$ & $\bar{v}_{l 6^{\prime}}$ & $\bar{v}_{l 1^{\prime}}$ & $\bar{v}_{l 2^{\prime}}$ & $\bar{v}_{l 3^{\prime}}$ \\
\hline
\end{tabular}

\section{THE PROPOSED METHOD OF SELECTED OPTIMAL VOLTAGE VECTOR}

DTC drive system provides the reliability of control performance by using selected voltage vector to control the torque and stator flux response. In the hysteresis torque controller, the large torque error may occur due to the large demand of torque reference. Hence, the increase torque is produced as the status of torque error is large performed by the torque controller. Two-level inverter or conventional inverter produces six active voltage vectors with different angle but same magnitude. Thus, the ability to control torque and stator flux of DTC is limited due to the single option amplitude of voltage vector by conventional inverter. As result, the DTC performance is degraded that may cause the large toque ripple and switching frequency especially at low operating speed. Fortunately, MLI topology provides numerous voltage vector that enables to manage the low operating speed problem as it offers various magnitude of voltage vector. The opportunity to improve the torque ripple and switching frequency is high plus the drive system can be performed in the various operating speed using DTC-MLI. In DTC hysteresis-based drives, the analysis of torque control behavior, $\mathrm{T}_{\mathrm{e}, \mathrm{n}}$ realized using the applied voltage vector on different speed operation is expressed as in (3) as shown in Figure 5, where $V_{s, n}$ and $\alpha_{\text {sk,n }}$ are the magnitude and angle of applied voltage respectively, $\bar{\varphi}_{\mathrm{s}, \mathrm{n}-1}$ is the stator flux vector at sample time $(n-1), \bar{\varphi}_{\mathrm{r}, \mathrm{n}}$ is the rotor flux vector at sample time $\mathrm{n}, \mathrm{C}$ is constant, $\theta_{\mathrm{r}, \mathrm{n}-1}$ and $\theta_{\mathrm{s}, \mathrm{n}-1}$ are the angle of rotor flux and stator flux respectively at sample time $(\mathrm{n}-1)$.

$$
\frac{\mathrm{dT}_{\mathrm{e}, \mathrm{n}}}{\mathrm{dt}}=\mathrm{C} \bar{\varphi}_{\mathrm{r}, \mathrm{n}}\left[\mathrm{V}_{\mathrm{s}, \mathrm{n}} \sin \left(\alpha_{\mathrm{sk}, \mathrm{n}}-\theta_{\mathrm{r}, \mathrm{n}-1}\right)-\omega_{\mathrm{s}} \bar{\varphi}_{\mathrm{s}, \mathrm{n}-1} \cos \left(\theta_{\mathrm{s}, \mathrm{n}-1}-\theta_{\mathrm{r}, \mathrm{n}-1}\right)\right]
$$




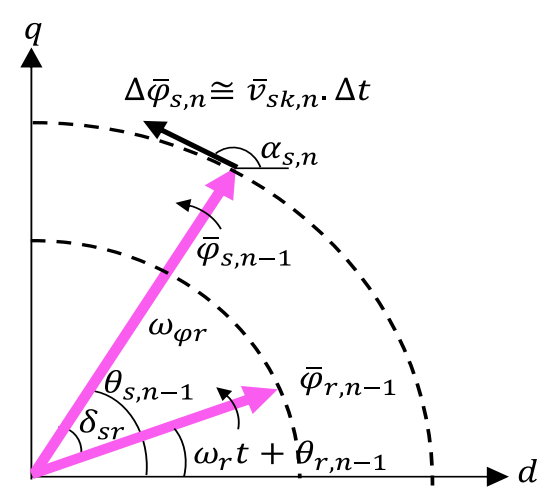

Figure 5. The reference of stator flux vector control traced with the appropriate voltage vector

In the practical of low operating speed, when the slip is assumed to be small, the angle of both rotor flux and stator flux becomes equal. Hence, the second term or reduction term in (3) is abandoned due to the neglected speed or angular frequency. Therefore, the largest tangential component of $\alpha_{\mathrm{sk}, \mathrm{n}}-\theta_{\mathrm{r}, \mathrm{n}-1}=90^{\circ}$ to the rotor or stator flux vector achieved by the applied voltage vector represents the increment of torque. It is verified that the applied voltage vector firmly affects the increment rate of torque performance. However, by considering the speed or angular frequency, the torque increment tends to be larger at lower speeds, or else it tends to be smaller. On the contrary, toward to the high operating speed, the second term or reduction term in (3) becomes significant, Thus, the stator flux angle has a slower rate to increase as apply the voltage vector in which the smaller increment of torque is generated at high speed operations.

As aforementioned, the large toque ripple and switching frequency may occur because of the following reason; 1) rapid increase torque due to the smaller value in the second term of equation (3) as the speed decreases, and 2) rapid decrease torque which occurs on each time of lower band is touched by the torque error in the three-level hysteresis comparator. Thus, the analysis is implemented by comparing the torque performance by using applied voltage between conventional DTC (two-level inverter) and the proposed method (five-level CHB inverter). As shown in the Figure 5, the employment of particular voltage vector produces the desired load angle performed by the difference angle of stator and rotor flux vector where the stator flux vector leads to the rotor flux vector. In simplify, the torque performance can be controlled by controlling the stator flux vector movement and the rate of change of load angle, $\delta_{\mathrm{sr}}$. The analysis is tested under the variation of motor load which is adjusted according to the selected voltage vector suggested by the proposed method.

\subsection{The analysis of proposed method}

If the longest amplitude voltage vector employs at very low operating speed, the stator flux achieves the greater rate of angle than the rotor flux resulting to occur the rapid increase torque. Yet again, the second term in (3) tends to be smaller which the reduction term becomes irrelevant. This incident is noticed in the conventional DTC which the active voltage vectors has no choice to select the single choice of amplitude vector (i.e. the longest amplitude of vector) to perform at very low operating speed. In order to solve the increase torque, the proposed method suggest the shortest amplitude of voltage vector so that the rate load angle, $\Delta \delta_{\mathrm{sr}}$ of increase torque reduces. Fortunately, the undershoot incidence where the lower band touched by torque error in the hysteresis comparator can be avoided. As a result, the lower torque ripple and switching frequency are achieved. For the case of decrease torque at very low operating speed, the proposed method has maintained the zero-voltage vector as apply in the conventional DTC. It performs the smaller rate of decrease torque when employs the proposed vector. Thus, the second or reduction term in (3) which represents the rate of torque becomes irrelevant as the speed decreases. It is noticed that the zero-voltage vector in the proposed method also applies to the stator flux where it turns to increase or decrease slowly or to halt.

Starting from low operating speed, there are two conditions required by voltage vector to emphasize; 1) prevent the rapid torque changes and, 2) maintain the torque control capability. The longest amplitude that employed by conventional DTC has caused the extreme increase torque which it brings effect to the large torque ripple and high switching frequency. There are two options of voltage vector offered in the proposed method; 1) shortest and, 2) short amplitude voltage vector. The shortest amplitude voltage vector is not suitable because the capability to achieve the demand is restricted due to the insufficient of stator flux 
vector to increase further to maintain the desired load angle. Thus, the proposed method has employed the short amplitude of voltage vector so that the range of stator flux angular frequency is extended in order to fulfil the two conditions as described previously. Meanwhile, for the decrease torque, the conventional DTC has applied zero voltage vector which it reduces the load angle at higher rate directly decreases the torque drastically. It is due to the possibility of stator flux tends to be halt as the rotor flux maintains moving towards to the stator flux vector. For that reason, the shortest amplitude of voltage vector is employed to minimize the rate of load angle in the proposed method. It is noticed that the rate of increase and decrease torque by using proposed vectors are minimized that enables to reduce the torque ripple as well as the switching frequency.

The aforementioned concept also implements into the medium-low, medium-high, high and very high operating speed. Just for the case at very high operating speed, the proposed method has applied the longest amplitude of voltage vector which is similar to the conventional DTC. So that, it increases the rotor flux angular velocity directly forcing the stator flux vector to have rapid rotation in order to retain the desired load angle at higher angular frequency. In addition, the reduction term in (3) tends to be large that makes the rapid increase torque produced by the longest amplitude of vector is not occurred. On the contrary to the decrease torque, the zero-voltage vector applied by conventional DTC causes the drastically reduce negative torque slope and the rate of load angle. Thus, the medium-short amplitude of voltage vector is suggested in the proposed method. It is the best selection among the rest where the large torque ripple and high switching frequency can be minimized as well as it retains the torque regulation on it reference. The decision of the selected voltage vector according to the operating speed is summarized in the Table 2.

Table 2. The summary of selected voltage vector based on each operating speed

\begin{tabular}{cccc}
\hline Operating Speed & Type of Voltage Vector & Voltage Vector & Remark \\
\hline Very Low & Shortest & $\bar{v}_{s 1}, \bar{v}_{s 2}, \bar{v}_{s 3}, \bar{v}_{s 4}, \bar{v}_{s 5}, \bar{v}_{s 6}$ & Increase torque \\
Low & Zero & $\bar{v}_{0}$ & Decrease torque \\
Medium-Low & Short & $\bar{v}_{s 1^{\prime}}, \bar{v}_{s 2^{\prime}}, \bar{v}_{s 3^{\prime}}, \bar{v}_{s 4^{\prime}}, \bar{v}_{s 5^{\prime}}, \bar{v}_{s 6^{\prime}}$ & Increase torque \\
& Shortest & $\bar{v}_{s 1}, \bar{v}_{s 2}, \bar{v}_{s 3}, \bar{v}_{s 4}, \bar{v}_{s 5}, \bar{v}_{s 6}$ & Decrease torque \\
Medium-short & $\bar{v}_{m 1}, \bar{v}_{m 2}, \bar{v}_{m 3}, \bar{v}_{m 4}, \bar{v}_{m 5}, \bar{v}_{m 6}$ & Increase torque \\
Medium-High & Shortest & $\bar{v}_{s 1}, \bar{v}_{s 2}, \bar{v}_{s 3}, \bar{v}_{s 4}, \bar{v}_{s 5}, \bar{v}_{s 6}$ & Decrease torque \\
& Medium-long & $\bar{v}_{m 1^{\prime}}, \bar{v}_{m 2^{\prime}}, \bar{v}_{m 3^{\prime}}, \bar{v}_{m 4^{\prime}}, \bar{v}_{m 5^{\prime}}, \bar{v}_{m 6^{\prime}}$ & Increase torque \\
High & Medium-short & $\bar{v}_{m 1}, \bar{v}_{m 2}, \bar{v}_{m 3}, \bar{v}_{m 4}, \bar{v}_{m 5}, \bar{v}_{m 6}$ & Decrease torque \\
& Long & $\bar{v}_{l 1}, \bar{v}_{l 2}, \bar{v}_{l 3}, \bar{v}_{l 4}, \bar{v}_{l 5}, \bar{v}_{l 6}$ & Increase torque \\
Very High & Medium-short & $\bar{v}_{m 1}, \bar{v}_{m 2}, \bar{v}_{m 3}, \bar{v}_{m 4}, \bar{v}_{m 5}, \bar{v}_{m 6}$ & Decrease torque \\
& Longest & $\bar{v}_{l 1^{\prime}}, \bar{v}_{l 2^{\prime}}, \bar{v}_{l 3^{\prime}}, \bar{v}_{l 4^{\prime}}, \bar{v}_{l 5^{\prime}}, \bar{v}_{l 6^{\prime}}$ & Increase torque \\
& Medium-short & $\bar{v}_{m 1}, \bar{v}_{m 2}, \bar{v}_{m 3}, \bar{v}_{m 4}, \bar{v}_{m 5}, \bar{v}_{m 6}$ & Decrease torque \\
\hline
\end{tabular}

\section{RESULTS AND DISCUSSIONS}

Further, the analysis of selected voltage vector on each operating speed is realized by using simulation setup. It involves the comparison of torque performance between conventional DTC (two-level inverter) and proposed method (five-level CHB inverter). MATLAB/Simulink package is applied to verify the effectiveness of analysis as constructed in Figure 6. The analysis is conducted on the three-phase induction motor as listed in Table 3. Meanwhile, DC-Link voltage source for both inverters are supplied at $220 \mathrm{~V}$. The torque of DTC is set to the reference of $1.55 \mathrm{Nm}$ and implemented on six operating speed at constant torque region. The speed is adjusted based on the motor load that is affected by the selected voltage vector. That means the variation of speed is estimated through the switching frequency performance observed from the response of phase voltage. Therefore, the simulation results are performed into torque, Te (upper) and phase voltage, Vs (bottom). All results are illustrated into magnified figure for better observation and comparison.

Table 3. The list parameter of induction machine

\begin{tabular}{cccc}
\hline & \multicolumn{4}{c}{ Induction Machine } \\
\hline Rated power, $P$ & $1.1 \mathrm{~kW}$ & Frequency, $f$ & $50 \mathrm{~Hz}$ \\
Rated speed, $\omega_{m(\text { rated })}$ & $2800 \mathrm{rpm}$ & Stator self-inductance, $L_{s}$ & $0.47979 \mathrm{mH}$ \\
Rated torque, $T_{e(\text { rated })}$ & $4 \mathrm{Nm}$ & Rotor self-inductance, $L_{r}$ & $0.47979 \mathrm{mH}$ \\
Rated flux, $\varphi_{s}$ (rated $)$ & $0.8452 \mathrm{~Wb}$ & Mutual inductance, $L_{m}$ & $0.4634 \mathrm{mH}$ \\
Stator resistance, $R_{s}$ & $6.1 \Omega$ & Combined Inertia, $J$ & $0.0565 \mathrm{~kg} . \mathrm{m}^{2}$ \\
Rotor resistance, $R_{r}$ & $6.2293 \Omega$ & Numbers of pole pairs & 1 \\
\hline
\end{tabular}




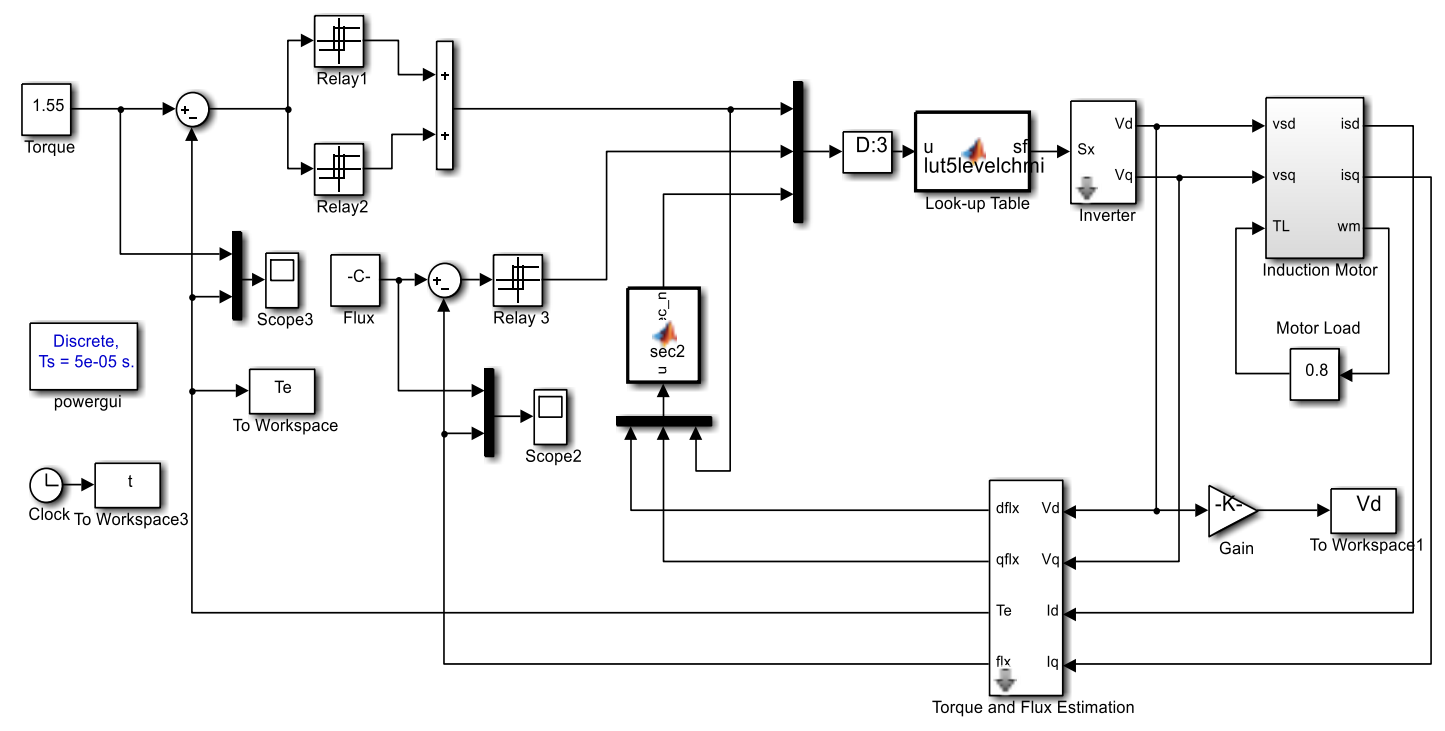

Figure 6. The simulation setup of DTC by using MATLAB/Simulink

At the beginning of very low operating speed, it is clearly seen in Figure 7 that the longest amplitude of voltage vector applied in the conventional DTC performs the rapid increase torque which turns to enlarge the ripple of torque performance. The ripple in increase torque is highly reduced about $55 \%$ by using the shortest voltage vector in the proposed method. For the decrease torque, both methods apply zerovoltage vector in order to be applicable at the lower rate torque of negative torque slope. At the same time, the low switching frequency as shown in Figure 7 is achieved by using the proposed method observed from phase voltage waveform. The amplitude of phase voltage is highly reduced due to the selected vector in the proposed method. The motor load is adjusted into $0.2 \mathrm{Nm}$ to generate at very low operating speed. On the other hand, at low operating speed shown in Figure 8, the conventional DTC still maintains the rapid torque during increase that suggests the proposed method to apply the short voltage vector to improve the performance. During the speed, the motor load is tuned at $0.055 \mathrm{Nm}$. On the contrary to the decrease torque, the negative torque slope in the proposed method becomes flat due to the shortest voltage vector rather than zero-voltage vector applied by conventional DTC. It is essential to avoid the extreme load angle rate and negative torque slope reduction. As a result, the approximation of $45 \%$ is occurred on the decrement of torque. In addition, the lower phase voltage and torque regulation are also achieved at low operating speed.

Meanwhile, by adjusting the motor load at $0.05 \mathrm{Nm}$, the motor able to generate at medium-low operating speed as shown in Figure 9, where the lesser steep of torque (increase or decrease) occurs in the conventional DTC rather than previous speed. To enhance the performance, the medium-short and the shortest amplitude of voltage vector are employed in the proposed method for the increase and decrease toque respectively. Thus, the low torque ripple and regulation with the reduction about $30 \%$ is achieved. The pattern of phase voltage is different due to the selected voltage vector with the decrease amplitude in the proposed method. At medium-high operating speed shown in Figure 10, the motor load is modified at $0.017 \mathrm{Nm}$. Certainly, the conventional DTC shows the pattern of torque performance as similar to the previous speed. Therefore, the proposed method has improved the torque by using medium-long voltage vector (increase torque) and medium-short voltage vector (decrease torque). The selected voltage vector in the proposed method has performed the reduction of torque at around 10\%. It is observed that torque ripple pattern (positive and negative) becomes smooth through the magnified result in Figure 10. In addition, the amplitude of phase voltage slightly decreases with low switching frequency in the proposed method rather than conventional DTC.

Alternatively, for high operating speed as shown in Figure 11, with the motor load is $0.015 \mathrm{Nm}$, the increase torque of conventional DTC is improved by using long voltage vector in the proposed method. Similar like the previous speed, the medium-short voltage vector is selected to the decrease torque because it enables to maintain the torque capability and minimize the torque ripple with approximate torque ripple reduction of $10 \%$. Therefore, the higher rate of load angle reduction can be prevented at negative torque slope. The different pattern of selected voltage vector can be observed in the Figure 11. By adjusting the motor load at $0.013 \mathrm{Nm}$, the motor generates at very high operating speed. During the speed, the same rate of increase torque shown in the magnified result of Figure 12 is performed due to the longest amplitude voltage 
vector applied by both methods (conventional and proposed). However, it is noticed that the conventional DTC produces the extreme torque decrease due to the application of zero voltage vector. In order to overcome the problem, the medium-short voltage vector is used to reduce the constrain of negative torque slope. As a result, the reduction of torque about $5 \%$ is achieved in the proposed method thus accomplish the low torque ripple and switching frequency at very high operating speed.
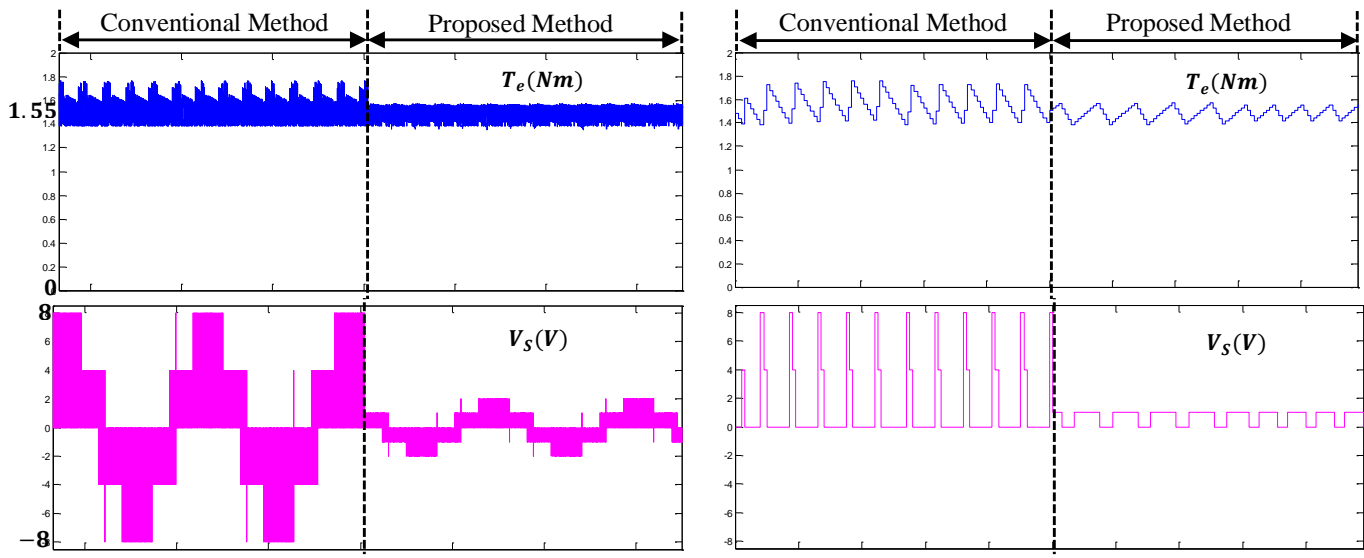

Figure 7. The simulation result (left) and magnified result (right) between conventional method and proposed method at very low operating speed
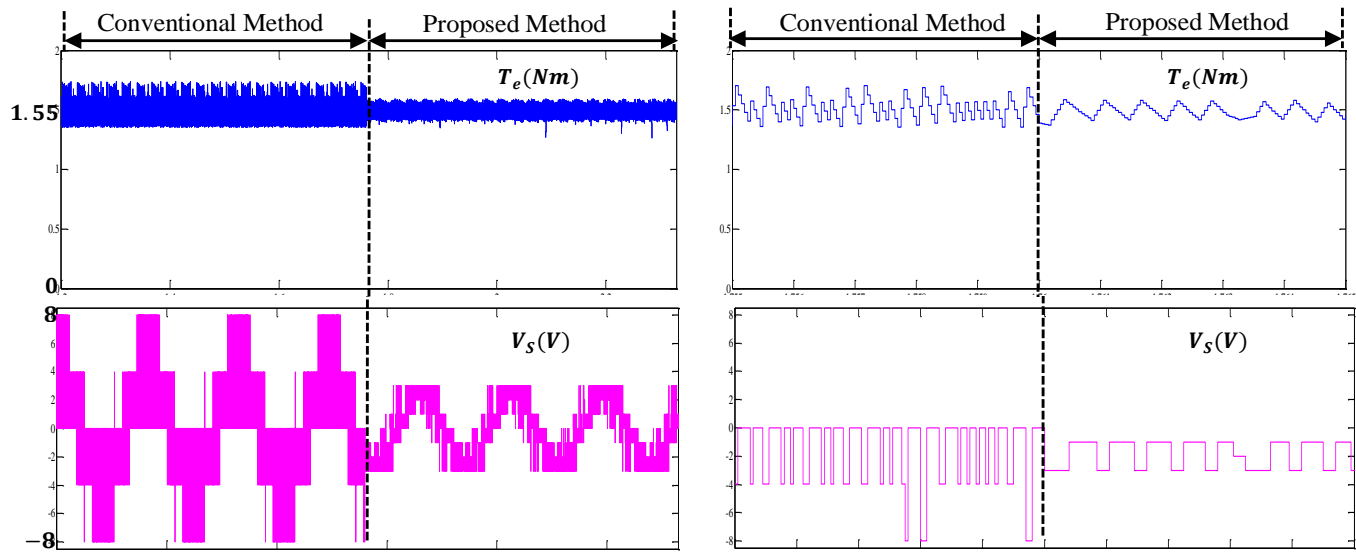

Figure 8 . The simulation result (left) and magnified result (right) between conventional method and proposed method at low operating speed
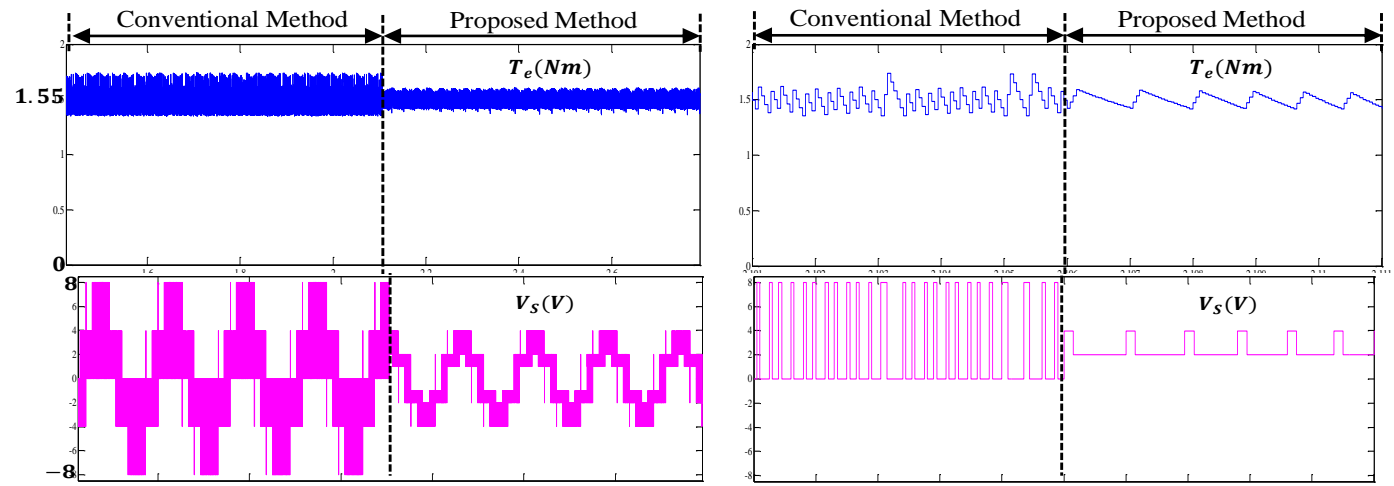

Figure 9. The simulation result (left) and magnified result (right) between conventional method and proposed method at medium-low operating speed 

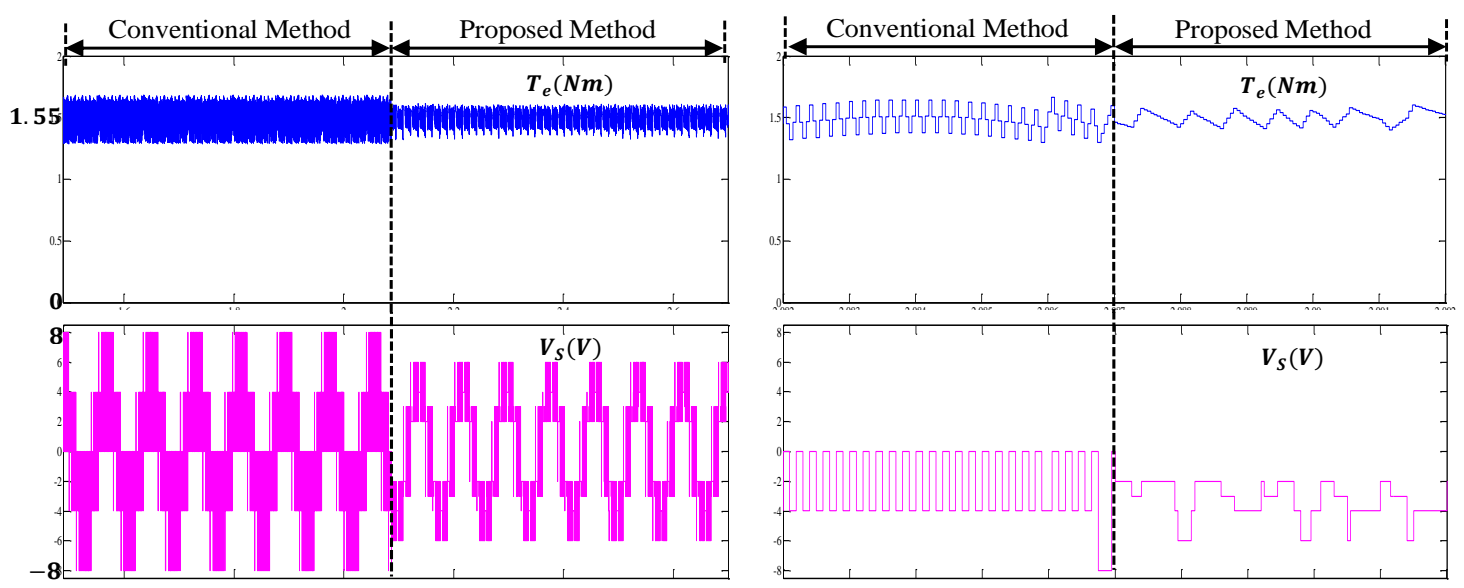

Figure 10. The simulation result (left) and magnified result (right) between conventional method and proposed method at medium-high operating speed
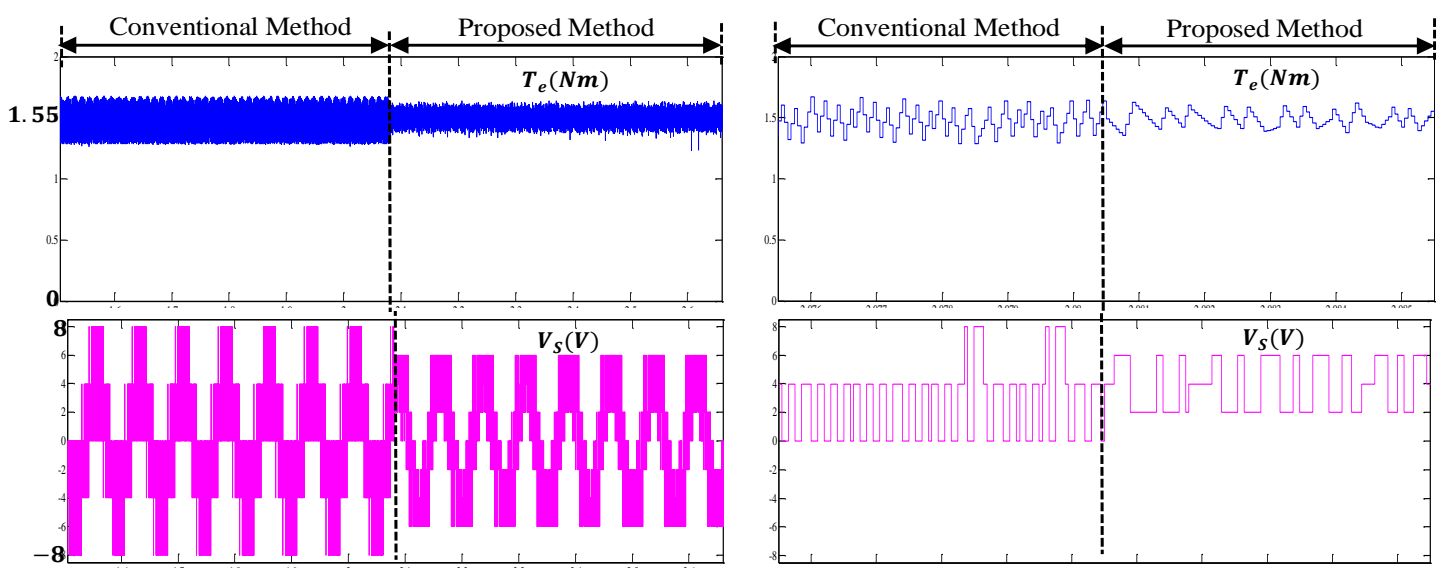

Figure 11. The simulation result (left) and magnified result (right) between conventional method and proposed method at high operating speed
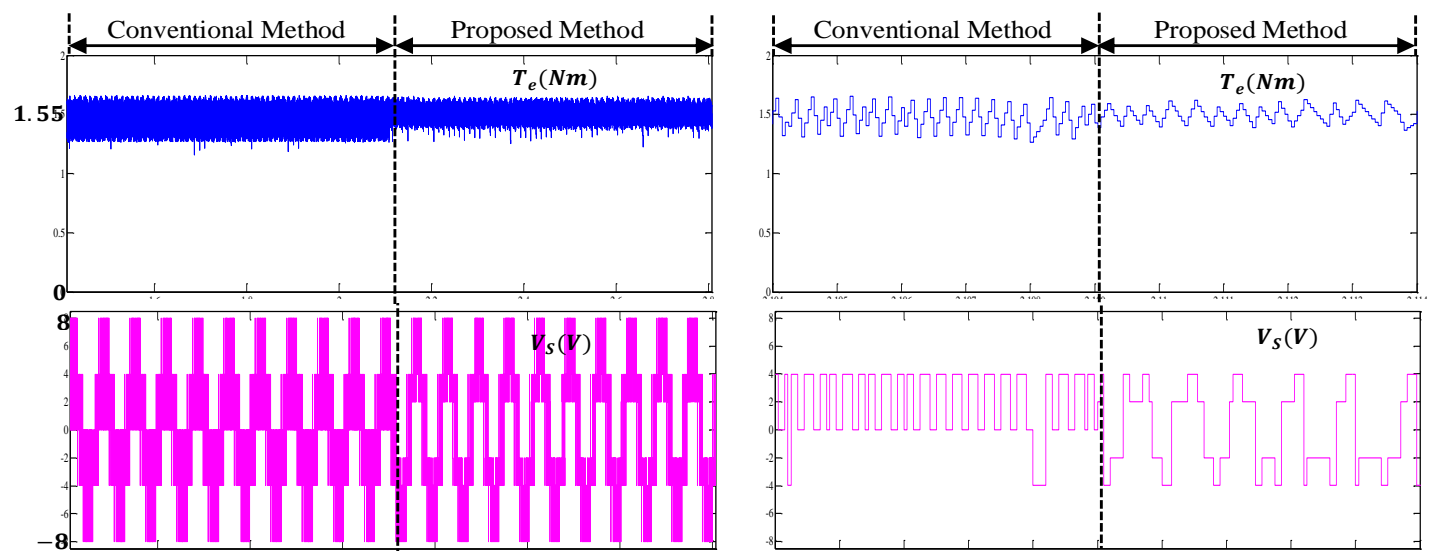

Figure 12. The simulation result (left) and magnified result (right) between conventional method and proposed method at very high operating speed 


\section{CONCLUSION}

The torque ripple reduction is achieved by using DTC hysteresis-based feeds MLI that can retain the simple structure of DTC. Five-level CHB inverter applied as a proposed strategy offers the numerous of different angle and magnitude of voltage vector. Thus, the look-up table DTC of five-level CHB inverter is constructed and guided to select the optimal voltage vector that is appropriate on the six types of operating speed at constant torque region. The speed controller is ignored, instead, the motor load is employed to control the speed which it must satisfy the optimal voltage vector. Furthermore, it must consider the increase and decrease torque of DTC performance. In order to verify the justification, the optimal voltage vector in the proposed method is analysed and compared with the conventional method (two-level inverter) through the simulation setup by using Simulink/MATLAB. From the simulation result, indeed, the torque ripple is able to be reduced and optimized as well the capability of torque keeps maintained on each operating speed even at low speed operation in the proposed method.

\section{ACKNOWLEDGEMENTS}

The authors gratefully acknowledge the financial support provided by the Ministry of Higher Education, Malaysia, (MOHE) and Universiti Teknikal Malaysia Melaka (UTeM).

\section{REFERENCES}

[1] B. K. Bose, "Scalar decoupled control of induction motor," IEEE Trans. Ind. Electron., vol. 31, pp. 216-225, 1984.

[2] G. S. Buja and M. P. Kazmierkowski, "Direct Torque Control of PWM Inverter-Fed AC Motors-A Survey," IEEE Trans. Ind. Electron., vol. 51, pp. 744-757, 2004.

[3] A. S. Abdel-Khalik, R. A. Hamdy, A. M. Massoud, and S. Ahmed, "Postfault control of scalar (V/f) controlled asymmetrical six-phase induction machines," IEEE Access, vol. 6, pp. 59211-59220, 2018.

[4] C. A. Costa et al., "Enhanced Braking Control for the Induction Machine Using Scalar Control," IEEE Trans. Ind. Electron., vol. 67, pp. 9133-9142, 2020.

[5] J. Bocker and S. Mathapati, "State of the Art of Induction Motor Control," 2007 IEEE Int. Electr. Mach. Drives Conf., vol. 2, pp. 1459-1464, 2007.

[6] C. Laoufi, Z. Sadoune, A. Abbou, and M. Akherraz, "New model of electric traction drive based sliding mode controller in field-oriented control of induction motor fed by multilevel inverter," Int. J. Power Electron. Drive Syst., vol. 11, pp. 242-250, 2020.

[7] M. Bouderbala, B. Bossoufi, A. Lagrioui, M. Taoussi, H. A. Aroussi, and Y. Thedrane, "Direct and indirect vector control of a doubly fed induction generator based in a wind energy conversion system," Int. J. Electr. Comput. Eng., vol. 9, pp. 1531-1540, 2019.

[8] C. D. Tran, P. Brandstetter, M. C. H. Nguyen, S. D. Ho, B. H. Dinh, and P. N. Pham, "A robust diagnosis method for speed sensor fault based on stator currents in the RFOC induction motor drive," Int. J. Electr. Comput. Eng., vol. 10, pp. 3035-3046, 2020.

[9] V. T. Ha, N. T. Lam, V. T. Ha, and V. Q. Vinh, “Advanced control structures for induction motors with ideal current loop response using field oriented control," Int. J. Power Electron. Drive Syst., vol. 10, pp. 1758-1771, 2019.

[10] R. H. Kumar, A. Iqbal, and N. C. Lenin, "Review of recent advancements of direct torque control in induction motor drives - a decade of progress," IET Power Electron., vol. 11, pp. 1-15, 2018.

[11] I. Takahashi and T. Noguchi, "A New Quick-Response and High-Efficiency Control Strategy of an Induction Motor," IEEE Trans. Ind. Appl., vol. IA-22, pp. 820-827, 1986.

[12] S. Kouro et al., "Recent Advances and Industrial Applications of Multilevel Converters," IEEE Trans. Ind. Electron., vol. 57, pp. 2553-2580, 2010.

[13] D. Roy, S. Kumar, and M. Singh, "A novel region selection approach of SVPWM for a three-level NPC inverter used in electric vehicle," Int. J. Power Electron. Drive Syst., vol. 10, pp. 1705-1713, 2019.

[14] G. Shashibhushan and S. Sonoli, "Starting torque and torque ripple reduction using SVPWM based vector control of induction motor with nine-level cascaded multilevel Inverter fed with solar PV power," Int. J. Power Electron. Drive Syst., vol. 10, pp. 1123-1132, 2019.

[15] W. A. Halim, S. Ganeson, M. Azri, and T. N. A. T. Azam, "Review of Multilevel Inverter Topologies and Its Applications," J. Telecommun. Electron. Comput. Eng., vol. 8, pp. 51-56, 2016.

[16] N. Prabaharan and K. Palanisamy, "A comprehensive review on reduced switch multilevel inverter topologies , modulation techniques and applications," Renew. Sustain. Energy Rev., vol. 76, pp. 1248-1282, 2017.

[17] M. K. Rahim, A. Jidin, and T. Sutikno, "Enhanced torque control and reduced switching frequency in direct torque control utilizing optimal switching strategy for dual-inverter supplied drive," Int. J. Power Electron. Drive Syst., vol. 7, pp. 328-339, 2016.

[18] M. A. Usta, H. I. Okumus, and H. Kahveci, "A simplified three-level SVM-DTC induction motor drive with speed and stator resistance estimation based on extended Kalman filter," Electr. Eng., vol. 99, pp. 707-720, 2017.

[19] B. R. Vinod, M. R. Baiju, and G. Shiny, "Five-Level Inverter-Fed Space Vector Based Direct Torque Control of Open-End Winding Induction Motor Drive," IEEE Trans. Energy Convers., vol. 33, pp. 1392-1401, 2018.

[20] S. A. L. Ramahlingam, A. Bin Jidin, T. Sutikno, and L. L. Raj, "Improvise 3-level DTC of induction machine using

\footnotetext{
The simulation analysis of torque ripple reduction by using optimal voltage vector... (Siti Azura A. Tarusan)
} 
constant switching frequency method by utilizing multiband carrier," Int. J. Power Electron. Drive Syst., vol. 7, pp. 638-647, 2016.

[21] D. Mohan, X. Zhang, and G. H. B. Foo, “A Simple Duty Cycle Control Strategy to Reduce Torque Ripples and Improve Low-Speed Performance of a Three-Level Inverter Fed DTC IPMSM Drive," IEEE Trans. Ind. Electron., vol. 64, pp. 2709-2721, 2017.

[22] A. Rahmati, M. Arasteh, S. Farhangi, and A. Abrishamifar, "Flying capacitor DTC drive with reductions in common mode voltage and stator overvoltage," J. Power Electron., vol. 11, pp. 512-519, 2011.

[23] S. Priya, A. Suresh, and M. R. Rashmi, "GCMT-249 Investigation and Performance Analysis of Direct Torque Control of 3phase Induction Motor using 7 Level Neutral Point Clamped Multilevel Inverter," Indian J. Sci. Technol., vol. 9, pp. 1-7, 2016.

[24] C. Lascu, I. Boldea, and F. Blaabjerg, "A modified direct torque control for induction motor sensorless drive," IEEE Trans. Ind. Appl., vol. 36, pp. 122-130, 2000.

[25] D. Mohan, X. Zhang, and G. H. Beng Foo, "Generalized DTC Strategy for Multilevel Inverter Fed IPMSMs with Constant Inverter Switching Frequency and Reduced Torque Ripples," IEEE Trans. Energy Convers., vol. 32, pp. 1031-1041, 2017.

[26] A. Jidin, K. A. Karim, K. Rahim, L. Raj, Logan Victor, S. Ramahlingam, and T. Sutikno, "A Review on Constant Switching Frequency Techniques for Direct Torque Control of Induction Motor," Indones. J. Electr. Eng. Comput. Sci., vol. 7, pp. 364-372, 2017.

[27] W. Chen, C.-L. Xia, Y.-Y. Zhao, Y. Yan, and Z.-Q. Zhou, "Torque Ripple Reduction in Three-Level Inverter-Fed Permanent Magnet Synchronous Motor Drives by Duty-Cycle Direct Torque Control Using an Evaluation Table," J. Power Electron., vol. 17, pp. 368-379, 2017.

[28] Y. Ren, Z. Q. Zhu, J. E. Green, Y. Li, S. Zhu, and Z. Li, "Improved Duty-Ratio-Based Direct Torque Control for Dual Three-Phase Permanent Magnet Synchronous Machine Drives," IEEE Trans. Ind. Appl., vol. 55, pp. 5843-5853, 2019.

\section{BIOGRAPHIES OF AUTHORS}
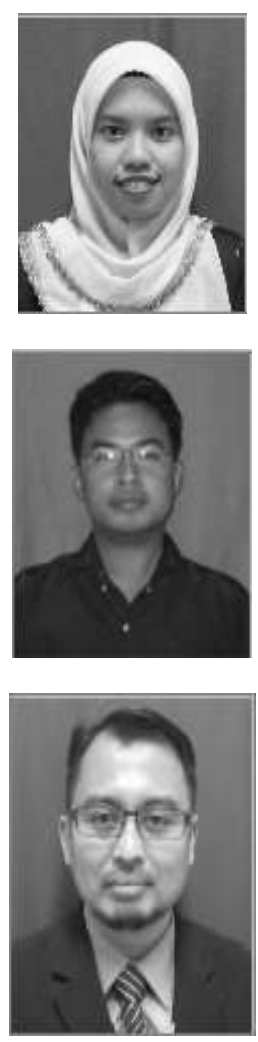

S. A. A. Tarusan received the B.Eng. degrees from Universiti Teknologi Malaysia, Johor Bahru, Malaysia, in 2008 and M.Eng. degrees from Universiti Malaya, Malaysia, in 2012. She is currently pursuing PhD under Power Electronics and Drives Research Group (PEDG) in the Faculty of Electrical Engineering, Universiti Teknikal Malaysia Melaka, Melaka, Malaysia. Her research interests include power electronics and motor drive systems.

A. Jidin received the B.Eng. degrees, M.Eng. degrees and Ph.D. degree in power electronics and drives from Universiti Teknologi Malaysia, Johor Bahru, Malaysia, in 2002, 2004 and 2011, respectively. He is currently an academician in Faculty of Electrical Engineering, Universiti Teknikal Malaysia Melaka, Melaka, Malaysia. He is also an active researcher in Power Electronics and Drives Research Group (PEDG) that established under the same faculty. His research interests include power electronics, motor drive systems, field-programmable gate array, and DSP applications.

M. L. M. Jamil received B.Eng. degree from the Universiti Teknologi MARA, Shah Alam, Malaysia, in 2000, M.Sc. degree from University of Newcastle upon Tyne, U.K., in 2003, and Ph.D. degree from The University of Sheffield, Sheffield, U.K., in 2011, all in electrical engineering. He is currently an academician in Faculty of Electrical Engineering, University Teknikal Malaysia Melaka, Melaka, Malaysia. He is also an active researcher in Power Electronics and Drives Research Group (PEDG) that established under the same faculty. His research interests include the design, control and analysis of permanent-magnet machines. 